\title{
KARAKTERISTIK STRUKTUR DAN KONSTRUKSI BANUA TAMBEN
}

\author{
A. Eka Oktawati*1, Hardi Ansyah ${ }^{2}$ \\ Arsitektur Universitas Islam Negeri Alauddin Makassar ${ }^{1,2}$ \\ e-mail:*1eka.oktawati@uin-alauddin.ac.id,2hardiansyah@gmail.com
}

\begin{abstract}
Abstrak_Banua Tamben merupakan rumah tongkonan generasi ketiga, konstruksi arsitektur banua tamben memiliki keunikan dibanding dengan rumah tongkonan saat ini. Penelitian ini bertujuan untuk menemukan karakteristik sistem struktur dan konstruksi arsitektur banua tamben yang mempresentasikan sistem konstruksi sebagai struktur, dengan fokus pada kajian terhadap proses penyusunan dan penggabungan bagian banua tamben sehingga membentuk sebuah banua tamben yang utuh. Metode penelitian dilakukan dengan penelitian kualitatif, dimana dalam penelitian ini digunakan teknik analisis deskriptif kualitatif. Hasil temuan memperlihatkan bahwa struktur dan konstruksi banua tamben yang tersusun dari beberapa bagian yaitu bagian bawah dan bagian atas. Secara keseluruhan banua tamben memiliki ciri khas konstruksi yang bisa disebut istilah "tamben", (bahasa Toraja = berselang-seling), yaitu menumpukkan balok melintang secara tumpang tindih dan berselang-seling sehingga membentuk struktur ruang pada kolom rumah.
\end{abstract}

Kata kunci: Banua; Tamben; Struktur; Konstruksi

\begin{abstract}
Banua Tamben is a third generation tongkonan house, the architectural construction of Banua Tamben is unique compared to the current tongkonan house. This study aims to find characteristics of the Banua Tamben architectural construction that presents the construction system as a structure, with a focus on the study of the process of compiling and joining parts of the Banua Tamben to form a complete Banua Tamben. The research method used is qualitative research, wherein this research qualitative descriptive analysis techniques are used as a technique in the analysis. The findings show that the structure and construction of the Banua Tamben are composed of several parts, namely the bottom and the top. Overall banua tamben has a characteristic construction which can be called the term tamben, (Toraja language = criss-cross), which is stacking transverse beams overlapping and crossing to form a spatial structure in the column of the house.
\end{abstract}

Keywords: Banua; Tamben; Structure; Construction.

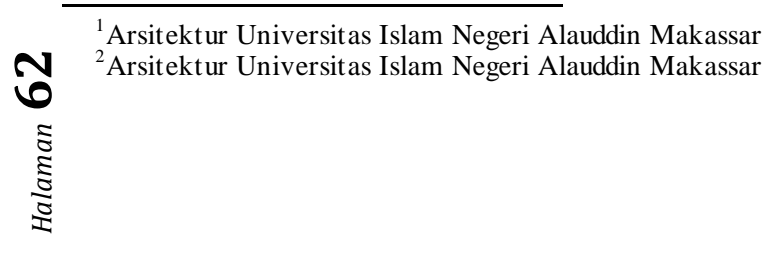




\section{PENDAHULUAN}

Rumah tradisional di Sulawesi Selatan memiliki ciri khas bentuk rumah panggung. Rumah tersebut telah diteliti oleh beberapa peneliti, menyimpulkan bahwa rumah panggung di Sulawesi Selatan terbagi menjadi tiga bagian yaitu bagian atas sebagai atap bangunan, bagian tengah sebagai badan bangunan dan bagian bawah sebagai kaki bangunan. Bentuk dari rumah tersebut dipengaruhi oleh badan yang tersedia, kondisi alam maupun pola hidup masyarakatnya. Bentuk struktur dan konstruksinya akan berbanding lurus dengan hal itu, tetapi cenderung memiliki karakteristik yang seragam, dimana bagian atas (atap) mengalirkan beban ke bagian badan bangunan dan diakhiri pada bagian bawah melalui struktur kaki bangunan (Sir, 2015).

Tana Toraja salah satu dari kekayaan Nusantara merupakan daerah yang mempunyai banyak rumah tradisional (Tongkonan) yang sudah berumur ratusan tahun dan dapat ditemukan diberbagai tempat di toraja. Arsitektur Tongkonan berkembang hingga mencapai bentuk yang sekarang melalui proses dalam kurun waktu lama dan sukar diketahui secara pasti sejarah dan konsep-konsep bentuk bangunannya dan strukturnya karena diturunkan dari generasi ke generasi tanpa peninggalan baik berupa gambar maupun tulisan. Demikian juga konsep-konsep pola pikir yang abstrak, kepercayaan, budaya, adat istiadat, iklim, lingkungan dan lain-lain bentuk arsitektural tidak dapat diketahui secara pasti.

Kemajuan teknologi, komunikasi, perhubungan, berbagai arsitektur tradisional mengalami perubahan-perubahan yang cenderung meninggalkan keasliannya. Perubahan-perubahan tersebut akan mengurangi bahkan dapat menghilangkan keaslian, keunikan dan keindahan yang sebetulnya justru menjadi daya tariknya, begitupun dengan tongkonan di Toraja.

Menurut beberapa ahli sejarah, rumah Toraja telah mengalami empat tahap perkembangan. Tahap pertama, disebut Banua Pandoko Dena', rumah pertama yang dikenal oleh orang Toraja, bentuknya agak membundar dengan dinding dan atapnya terbuat dari daun-daunan dan rumputrumputan mirip dengan sarang burung pipit. Tahap kedua, disebut Banua Lentong A'pa', rumah ini sudah mempunyai empat tiang pada keempat sudutnya, meskipun tiangnya belum begitu besar dan pada saat itu rumah masih relatif kecil. Penutup atap rumah ini masih sama dengan seperti banua pandoko dena'. Tahap ketiga, yaitu Banua Tamben, Menurut informasi yang didapatkan penulis banua tamben masih ada delapan yang tersebar di Toraja. Enam diantaranya merupaka hasil rekonstruksi yang terletak di kecamatan Bori' sisahnya berada di Sumalu Kecamatan Rantebua dan berada di Tonga' kecamatan Kesu'. Tahap keempat, disebut Banua Tolo' atau Sanda A'riri . (tolo'=ditusuk teratur dengan alat yang besar; di-sanda' = dilengkapkan; a'riri = tiang). Rumah ini merupakan tahap perkembangan dari banua tamben, dengan melibatkan alat-alat pertukangan modern yang tidak lagi terdiri dari susunan kayu berselang-seling tetapi hanya menggunakan beberapa buah tiang saja, dan mulai saat itu juga bangunan rumah sudah relative besar dan lebih memanjang. Sejak adanya banua tamben, bagian depan dan belakang bangunan menjulang ke atas, dan dinamakan longa', yang sampai sekarang menjadi ciri khas bentuk bangunan rumah adat Toraja (Said, 2004).

Penelitian mengenai rumah toraja sampai sekarang lebih banyak mengkaji rumah tongkonan dengan bentuk sekarang yang merupakan perkembangan dari Banua Tolo' atau Sanda A'riri. Sementara banua tamben belum ada yang sebelumnya mengkaji mengenai struktur dan konstruksinya, disebabkan karena keberadaan banua tamben sudah mulai punah dan rusak. Salah satu banua tamben yang masih bertahan yaitu berlokasi di Kampung Adat To Baulu, Tonga'. Oleh 
karena itu perlu adanya penelitian yang mengkaji tentang sistem struktur dan konstruksi Banua Tamben.

Kajian penelitian ini adalah mempresentasikan konstruksi Arsitektur Banua Tamben yang memiliki keunikan sistem struktur dan konstruksi yang sangat berbeda dengan rumah Tongkonan sekarang ini. Berdasarkan pendahuluan di atas, maka rumusan masalah studi ini adalah bagaimana karakteristik sistem struktur dan konstruksi Banua Tamben.

Tujuan penelitian untuk mendapatkan sistem konstruksi Banua Tamben terkait dengan penyusunan dan penggabungan tiap bagian dari Banua Tamben. Sehingga temuan yang diharapkan adalah sistem konstruksi dari arsitektur Banua Tamben.

Dengan adanya penelitian ini, diharapkan memberikan manfaat bagi penulis dalam hal sistem penelitian dan dapat dijadikan konsep perancangan agar warisan arsitektur Toraja tetap terjaga serta penelitian ini dijadikan sebagai acuan dalam penelitian Banua Tamben selanjutnya.

\section{METODE}

Penelitian ini menggunakan metode kualitatif,merupakan metode penelitian yang berlandaskan pada filsafat positivisme, digunakan untuk meneliti pada kondisi obyek yang alamiah (Sugiyono, 2010). Metode kualitatif yang digunakan yaitu memaparkan atau mendeskripsikan analisis sistem struktur dan konstruksi Banua Tamben berdasarkan fenomena yang terjadi di lapangan secara alamiah.

Data penelitian diperoleh dengan dua cara yaitu primer dan sekunder, data primer diperoleh dengan mengamati langsung pada objek di lapangan. Sedangkan data sekunder diperoleh dari data yang didapat tidak secara langsung dari objek penelitian, mencakup hasil pengkajian literatur, artikel, jurnal ilmiah, serta analisa peta maupun penerbitan yang relevan. Analisis data dilakukan dengan cara mengembangkan informasi/data secara deskripsi yang diperoleh dari data primer dan sekunder, kemudian menarik kesimpulan sebagai hasil dari penelitian.

Objek penelitian hanya terdiri dari 1 unit banua yang terletak di Kampung Adat To Baulu, Tonga'. Kecamatan Kesu' Toraja Utara dengan objek penelitian adalah Banua Tamben.

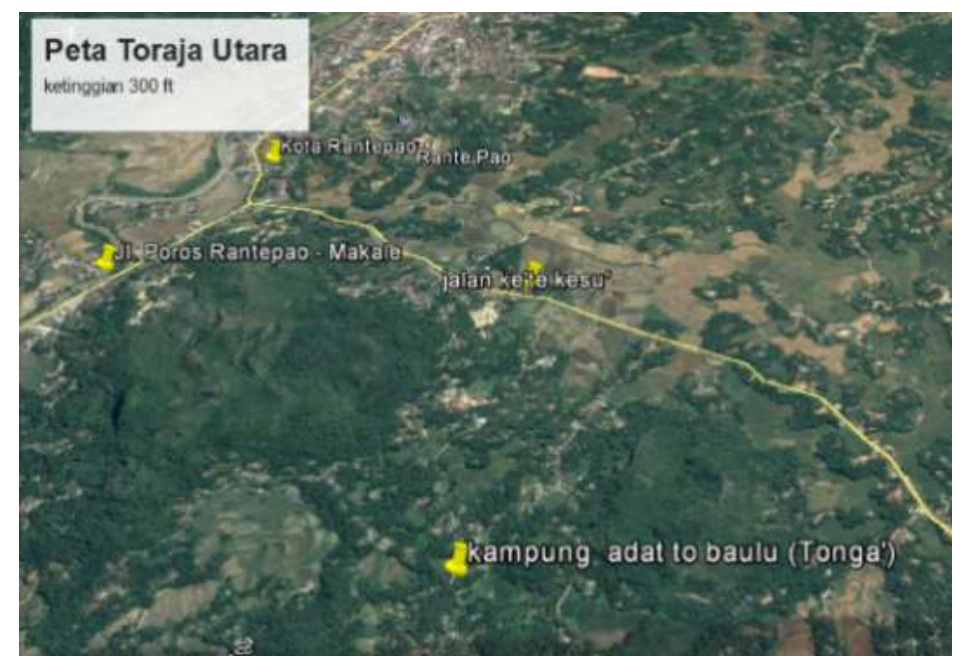

Gambar 1. Peta Lokasi Sumber: google earth , diakses juli 2017 


\section{HASIL DAN PEMBAHASAN}

\section{A. Banua Tamben}

Menurut Kis dkk (1988), tipologi bangunan Arsitektur Tradisional Toraja dibagi menjadi lima yaitu:

1. Tipe rumah tinggal (banua),

2. Tipe lumbung,

3. Tipe rumah penjaga di sawah,

4. Tipe Kandang, dan

5. Tipe bangunan pemakaman. Tiap tipe dapat dibagi lagi menjadi beberapa tipe sesuai dengan karakter atau tujuan konstruksinya

Arti rumah bagi masyarakat Toraja bukan sekedar sebagai tempat hunian tetapi memiliki berbagai fungsi dan makna. Rumah biasa di Toraja secara umum dinamakan "banua" atau "barung barung". yang dinyatakan dalam kutipan berikut :

Banua (wanua, benua) has an equallywide range of referents in modern Austronesian language, from "house" or "village" to "continent" and "cosmos". Sa'dan Toraja banua, for example, means "house". (banua/wanua/benua) memiliki arti yang luas dalam Bahasa Austronesia modern, mulai "rumah" atau "kampung" hingga "benua" dan "dunia". Masyarakat Sa'dan Toraja, misalnya menyebutnya banua, yang berarti rumah (Tangdilintin, 1978).

Banua tamben adalah generasi ketiga dari perkembangan rumah Toraja yang berfungsi sebagai rumah yang dibentuk dengan menyusun kayu-kayu secara berselang-seling pada setiap sisinya, kiri dan kanan serta depan belakang, dalam bentuk persegi empat panjang, yang menjadi konstruksi dasar dan sekaligus berfungsi sebagai dinding rumah. Hal ini sesuai dengan arti dari kata "tamben" yang berarti berselang-seling (Said, 2004).

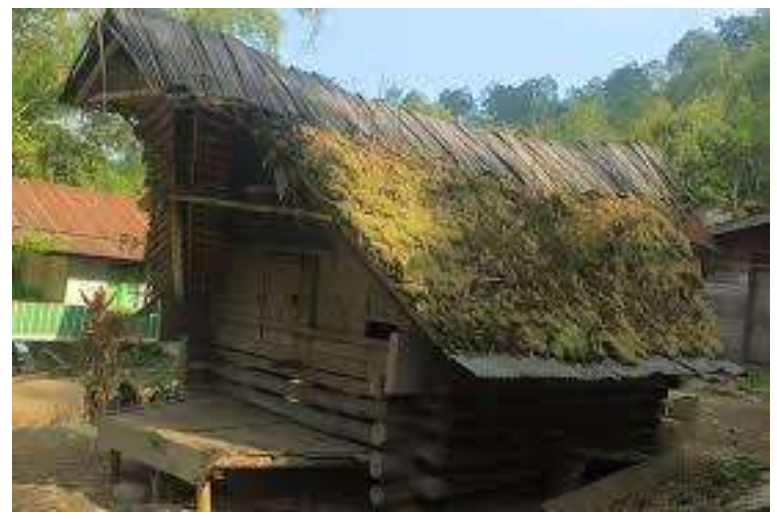

Gambar 2. Banua Tamben

Sumber: Dokumentasi, 2017

\section{B. Sistem Struktur dan Konstruksi Banua Tamben}

Secara vertikal struktur dan konstruksi tongkonan terbagi menjadi 3 bagian utama (Sir, 2015), yaitu:

1. Bagian kaki (sullu banua), menggunakan sistem rangka kolom dan balok. Kestabilan lengtong alla ini diperkuat oleh ikatan-ikatan lentur antara oleh balok roroan baba dan roroan lambe. Bagian bawah rumah difungsikan sebagai tempat memelihara ternak kerbau dan babi. 
2. Bagian badan rumah (kale banua), menggunakan sistem struktur siamma, sistem ini sama fungsinya dengan dinding pemikul beban, yang membedakannya adalah bahan dan penyusun dinding ini terbuat dari susunan papan. Bagian badan rumah difungsikan sebagai tempat untuk kegiatan fungsional sehari-hari.

3. Bagian atas (rattiang banua), merupakan atap rumah, sebagai penutup seluruh struktur rumah. Rattiang banua menggunakan sistem struktur bidang pada atap dan struktur rangka balok-kolom (rangka balok pada balok kaso, pada rangka kolom pada lentong garopa dan tulak somba). Bagian rattiang difungsikan sebagai tempat penyimpanan barang-barang seperti peralatan rumah tangga, kain dan lain sebagainya.

Menurut Ismanto dan Maria (2020), sistem struktur dan konstruksi, pada tiap bagian tongkonan disusun dan disatukan sehingga menjadi bangunan yang utuh, dengan cara tiap bagian didudukan dengan bagian lainnya, bermula dari sullu banua didudukkan di atas batu peradangan yang merupakan pondasi bangunan, kemudian bagian kale banua didudukkan di atas sullu banua, selanjutnya bagian atas rattiang banua didudukkan di atas kale banua.

Berbeda dengan struktur rumah Tongkonan yang pernah dikaji, Banua Tamben hanya terbagi menjadi dua sistem struktur yaitu:

1. Bagian bawah, terdiri dari pondasi dan kolom yang tersusun dari kayu melintang berselangseling. Bagian pondasi menggunakan batu yang diletakkan di atas tanah, berfungsi untuk menahan kolom dan sebagai pelindung dari air tanah. Kolom terbuat dari batang kayu buangin disusun secara melintang sampai empat susun dalam bahasa setempat disebut: distamben" sehingga membentuk sebuah ruang/kolom dengan sistem penyambungan tidak menggunakan paku . Bagian ini berfungsi sebagai kandang ternak seperti babi dan ayam.
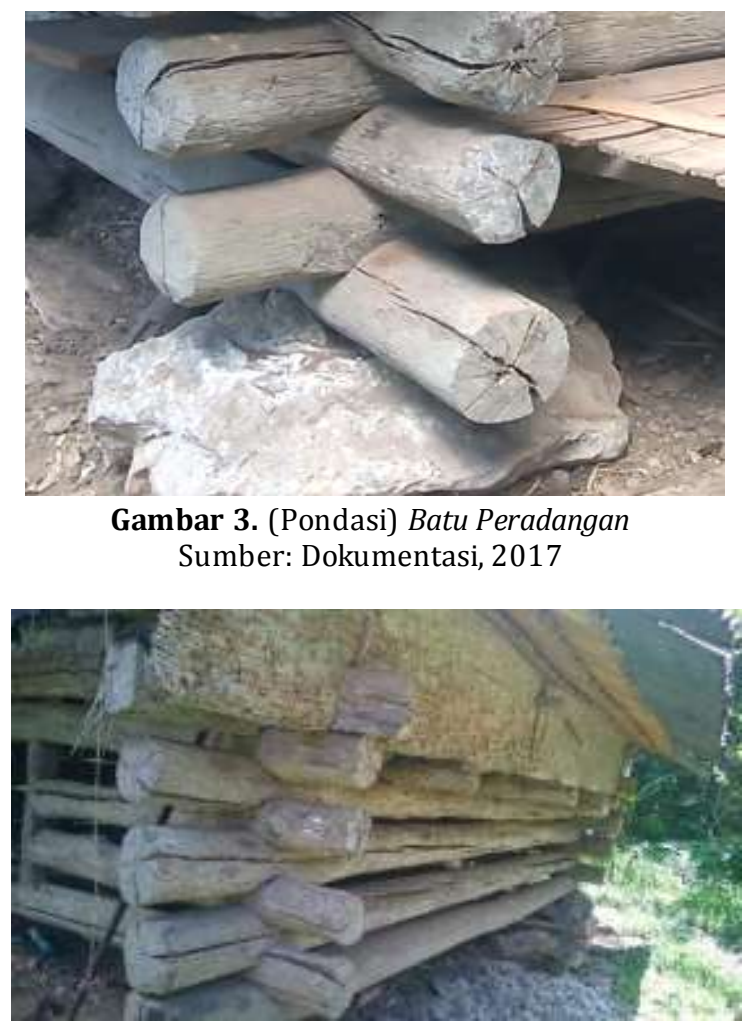

Gambar 4. Kolom Rumah Sumber: Dokumentasi, 2017 
2. Bagian atas, terdiri dari badan rumah yang menyatu dengan atap. Badan rumah berbentuk persegi panjang dengan dinding segitiga yang disebut para'. Badan rumah menyatu dengan atap sehingga membentuk struktur ruang dengan sistem tumpuk. Bentuk atap banua tamben telah mengalami perubahan bentuk dari generasi sebelumnya, yaitu bagian depan dan belakang atap sudah memanjang keluar tanpa penopang (tulak somba) seperti Tongkonan zaman sekarang.

\section{Proses Perakitan Banua Tamben}

Menyusun dan menyatukan bagian Banua Tamben menjadi satu kesatuan utuh, merupakan bagian yang sangat penting dalam menghadirkan sebuah banua sehingga dapat berdiri kokoh dan kuat terhadap penyaluran beban dan berbagai kendala pada sistem struktur dan konstruksi. Penggabungan bagian-bagian Banua Tamben dilakukan dengan cara memadukan elemen struktur dan nonstruktur sehingga membentuk bangunan yang estetis, elemen-elemen ini disebut sebagai konstruksi, seperti yang dikemukakan oleh menurut Taufik Priambodo dan Heinz Frick. Menyusun tiap elemen struktur dan konstruksi kolom, dengan sistem struktur rangka dimana kolom disusun secara melintang sehingga saling menguatkan antara satu dengan lainnya. Kekayaan tektonika Banua Tamben dimulai dari sistem struktur dan konstruksi bagian bawah bangunan, dimana batang pohon yang paling besar dipasang pada bagian paling bawah dan batang pohon ukuran kecil disusun melintang paling atas sehingga memberikan kekuatan yang kaku dan kokoh untuk dapat menahan beban vertikal maupun beban horizontal yang dipikul oleh kolom dan pondasi.

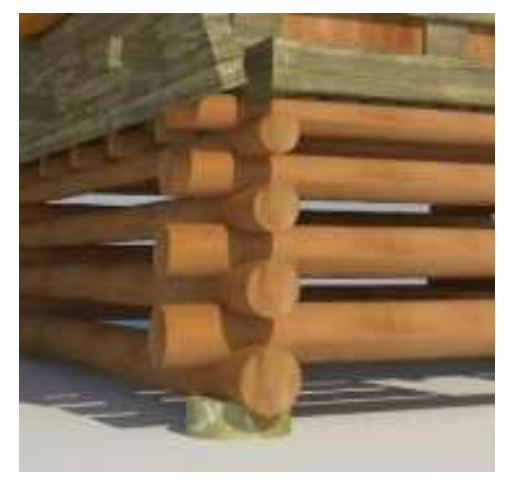

Gambar 5. Cara Penyusunan Balok Sumber: Ilustrasi Bentuk, 2017

Kolom banua tamben merupakan ciri khas dari banua ini, karena tersusun dari kayu utuh bulat tanpa polesan yang saling tumpang tindih secara berselang-seling membentuk sebuah ruang kolom. Bagian kayu yang tumpang tindih di setiap sudut diberi takikan supaya memperkuat dudukan akibat gaya horizontal. Diatas susunan balok melintang didudukkan badan rumah dengan bentuk geometri dasar persegi panjang. Dinding banua terdiri dari para' (dinding segitiga yang terletak pada bagian depan dan belakang banua). Atap banua sekaligus menjadi dinding bagian samping kanan dan kiri banua. Atap banua duduk di atas balok pipih yang melintang di atas kolom.

Bagian lantai rumah terbuat dari papan kayu kecil yang disusun dengan celah sekitar $1 \mathrm{~cm}$. Sistem sambungan yang digunakan adalah sistem ikat antara papan lantai dengan balok. Pengikat yang digunakan adalah rotan. Rotan merupakan material alami yang memiliki kemampuan kuat untuk mengikat yang sering dijumpai pada rumah tradisional khususnya rumah panggung. 


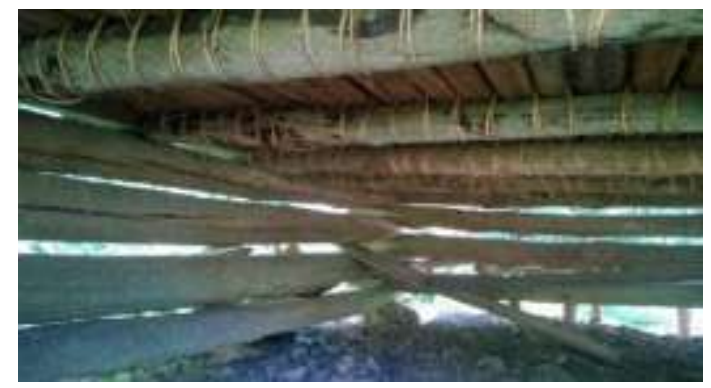

Gambar 6. Sistem Sambungan Balok dengan Lantai Rumah Sumber: Dokumentasi, 2017

Konstruksi dinding merupakan sistem siamma dimana kekuatan dinding bangunan berfungsi sebagai dinding struktur yang dapat memikul dan menyalurkan beban struktur, disebut sebagai konstruksi siamma, untuk mewakili sistem struktur dan konstruksi, sesuai dengan penelitian Mochsen Sir tahun 2015 dalam penelitiannya yang berjudul "Model Tektonika Arsitektur Tongkonan Toraja".

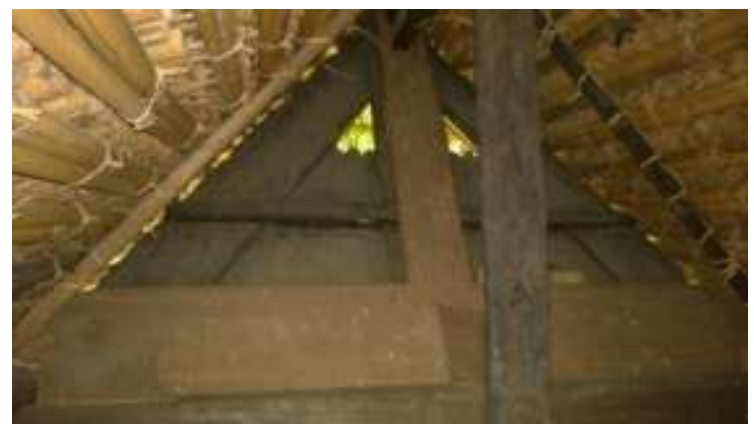

Gambar 7. Dinding segitiga (para) Sumber : Dokumentasi, 2017

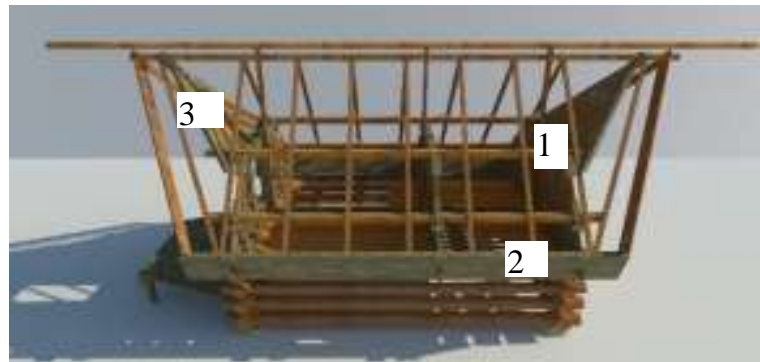

Gambar 8. Proses perakitan atap; 1. Kadang panuriang; 2. Kaso; 3.kadang para; Sumber : Ilustrasi Bentuk, 2017

Sistem konstruksi atap banua terdiri atas sambungan ikat, takik, pen-lubang, dan tanpa paku. Sistem struktur dan konstruksi atap lebih variatif dibandingkan dengan kolom dan badan rumah, karena bagian atap terdiri dari beberapa jenis material. Material penutup atap menggunakan bambu yang dibelah dua dan saling menumpuk berlapis-lapis. Perakitan bambu menggunakan sambungan ikat dengan tali rotan. Rangka kuda-kuda untuk atap mengikuti bentuk atap dengan menggunakan sambungan takik, pen dan lobang. 


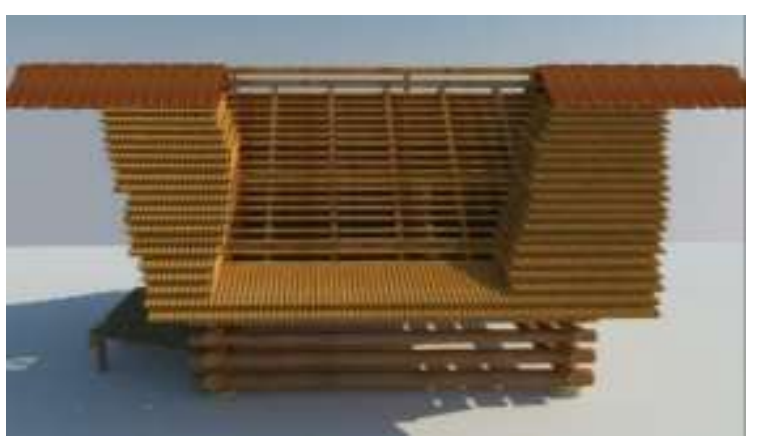

Gambar 9. Rangka atap Sumber : Ilustrasi Bentuk, 2017

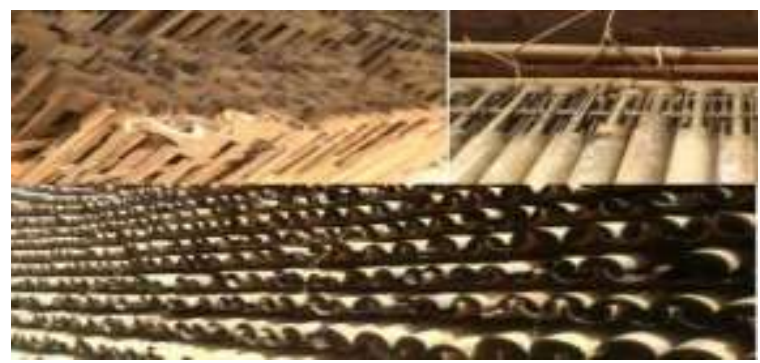

Gambar 10. Proses Penyambungan Bambu pada Bagian Penutup Atap Sumber : Dokumentasi, 2017

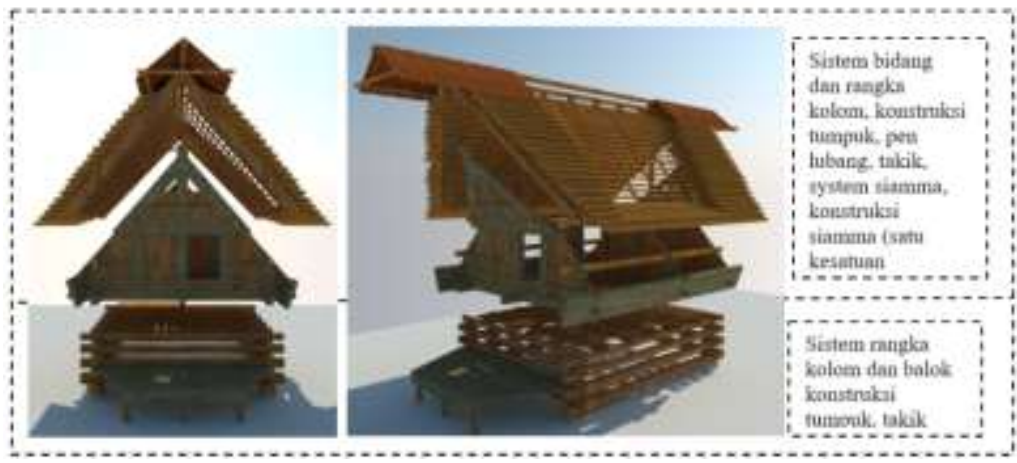

Gambar 11. System Konstruksi Banua Tamben Sumber : Ilustrasi Bentuk, 2017

\section{KESIMPULAN}

Banua tamben merupakan generasi ketiga dari rumah Tradisional Toraja yang sampai sekarang masih bisa ditemui dari beberapa daerah di Toraja. Banua ini adalah generasi sebelum Tongkonan seperti sekarang. Banua tamben dan Tongkonan memiliki perbedaan bentuk, khususnya dari bentuk kolom dan atap bangunan. Banua tamben memiliki sistem struktur yang terbagi menjadi dua, yaitu bagian bawah yang terdiri dari pondasi batu dan kolom yang terbuat kayu bulat. Sedangkan bagian atas terdiri dari badan rumah yang berbentuk prisma dan atap yang menjorok keluar tanpa penopang (sulluk banua). Setiap bagian banua ini menggunakan konstruksi tanpa alat modern seperti paku. Semua bagian elemen struktur saling menyatu dengan sistem sambungan kayu dan bambu seperti siamma, takik, menumpuk, ikat, pen dan lobang. Secara keseluruhan banua tamben memiliki ciri khas konstruksi yang bisa disebut istilah tamben, (bahasa Toraja = 
berselang-seling), yaitu menumpukkan balok melintang secara tumpang tindih dan berselangseling sehingga membentuk struktur ruang pada kolom rumah.

\section{DAFTAR REFERENSI}

Frick, Heinz. (1998). Sistem Bentuk Struktur Bangunan : Dasar-dasar konstruksi dalam Arsitektur. Yogyakarta : Kanisius

Ismanto, Riyadi. dan Maria, Margareta. Rumah Tongkonan Toraja Sebagai Ekspresi Estetika Dan Citra Arsitektural. (2020). Universitas Kristen Indonesia.

Kis, Jowa Imre. Nooy, Hetty. Schefold, Reimar \& Schulz, Ursula. 1988. Banua Toraja: Changing Patterns in Architecture and Symbolism among the Sa'dan Toraja Sulawesi Indonesia. Amsterdam: Royal Tropical Institute.

Priambodo T. (2009). Struktur \& Konstruksi Rumah Menengah. sumdhar arsitektur wrinter studio Said, Abdul Azis. (2004). Toraja Simbolisme Unsur Visual Rumah Tradisional. Yogyakarta: Ombak. Sir M.M dkk. (2015). Model Tektonika Arsitektur Tongkonan Toraja. Prosiding SNST ke-6.

Sugiyono. (2010). Metode Penelitian Pendidikan Pendekatan Kuantitatif, kualitatif, dan R\&D. Bandung: Alfabeta

Tangdilinting L. T. (1978). Tongkonan (Rumah Adat Toraja) dengan Struktur, Seni dan Konstruksinya, Yayasan Lepongan Bulan, Tana Toraja. 